\title{
The Professional Rugby Experience in England and Italy*
}

\author{
Howard Thomas $^{* *}$, Francesco Cavatorti $^{* * *}$, Alessandro Fino ${ }^{* * * *}$
}

\begin{abstract}
The Premier Rugby League is made up of 12 professional clubs. Its mission is to promote professional rugby in England. In fulfilling this mission, it bases all activities on the League's founding principles: a 'large virtual family' with values such as moral integrity. This strong sense of aggregation is a feature of the rugby community.

The spirit of collaboration has also developed at the international level formalised by an agreement with The Italian Rugby League-LIRE (Lega Italiana Rugby Eccellenza). Twinning between LIRE and Premier League means organisational and technical strengthening for each of their Clubs.
\end{abstract}

Keywords: Rugby; Sport Management; Events; Marketing; The Premier Rugby League; The Rugby Marketing Pyramid; Italian Rugby League; Global Markets

\section{The Premier Rugby League (PRL)}

The Premier Rugby League is made up of 12 professional clubs, from Northern to Southern England, all taking part in the Guinness Premiership. Its mission is to promote professional rugby in England. In fulfilling this mission, it bases all activities on the League's founding principles: a 'large virtual family' with attitudes such as moral integrity, respect not just for fellow players but for all those in the rugby community managers, associates, players, fans and the public as a whole. This strong sense of aggregation is a feature of the rugby community and lies behind its success.

The main purposes of the Premier Rugby League are to:

- manage commercial aspects and represent the professional English rugby clubs;

- promote rugby clubs, players and values to the public;

- create the most attractive and commercially successful sports league in the world.

\footnotetext{
* The Authors: H. Thomas $\S 1$; F. Cavatorti and A. Fino $§ 2$

** Chief Executive Officer Premier Rugby League (info@premiershiprugby.com)

*** General Secretary Lega Italiana Rugby Eccellenza (info@legarugby.it)

**** Marketing Dept. Lega Italiana Rugby Eccellenza (info@legarugby.it)
}

Edited by: ISTEI - University of Milan-Bicocca

ISSN: $1593-0319$

Thomas Howard, Cavatorti Francesco, Fino Alessandro, The Professional Rugby Experience in England and Italy, Symphonya. Emerging Issues in Management (symphonya.unimib.it), n. 2, 2004, pp. $81-88$

http://dx.doi.org/10.4468/2004.2.06thomas.cavatorti.fino 
More specifically, the objectives are to: increase revenue in general and from tickets in particular; public attendance at matches and the stadium fan profile; find new revenue forms; control costs; develop a well managed market; take part in developing the ERC (European Rugby Cup); win the ERC more often than other countries; develop control of rugby stadiums; promote a common European season; be increasingly responsible for activities; harmonise player relations; and increase value for club shareholders and the PRL.

In order to successfully achieve these objectives, there must be a proper winning approach - not just from a sports perspective but also from a financial one. The right approach is to run the PRL as though it were a company. The League wants to stimulate its clubs individually, thus ensuring efficiency for the group as a whole.

\subsection{The Main 'Evolutionary' Stages for Premier Rugby Clubs}

Premier Rugby has highlighted certain activities to be promoted within each club, split into three stages:

1. the productivity stage, in which club shareholders need to be given a return on their investment. This means understanding the market, in this case fans, their needs and trying to satisfy them to the best degree possible, managing relations with sponsors and transmitting the club image positively. All these variables help produce a financial return, important for club survival;

2. the development stage. After having generated productivity, clubs have to keep a high profile. To do this they need to control costs, for example, by setting salary caps and by going into partnership with other clubs to help each other become stronger. This allows them to improve activity standards, thereby ensuring long-term success and competitiveness;

3 . the investment stage. After getting greater control over the business, clubs are then able to develop 'strategies' in creative areas. Each club is an economic entity with investment potential. Sport needs to have projects and clubs must combine their strength so as to invest in more projects.

These three stages highlight the road to success. Today, Premier Rugby has 12 really strong clubs. We must acknowledge that a League's strength is not just based on 2 or 3 clubs but on all of them and at the same level. Of special note is that, over the past five years, League club income has doubled from $£ 15$ million to $£ 30$ million; the commercial value of clubs has increased to $£ 80$ million (about $€ 120$ million); average spectator attendance has gone from 6,000 to 10,000 (Figure 1); there have been four English victories in the European Cup over five years; the number of clubs in the black has gone from one to five; Premier Rugby is now amongst the best sports in the world.

Premier Rugby management concentrated all its resources, human and financial, so that the Premiership is now considered one of the best competitions in the world. For this to happen, the Premier Rugby organisation had to evolve to a high professional level. They worked on unifying policies between clubs and with the players' union. But a successful sports organisation is not just a matter of generating profits. Success mainly comes from its ability to create value for users. That is why the Premier Rugby League works hard on relations with fans and with the community it belongs to. 
Figure 1: Average Premier Rugby Attendances

\begin{tabular}{|c|c|c|}
\hline Season & $\begin{array}{c}\text { Average no. of } \\
\text { Spectators }\end{array}$ & Annual Variation \% \\
\hline $1998 / 99$ & 5,507 & - \\
\hline $1999 / 00$ & 5,702 & $4 \%$ \\
\hline $2000 / 01$ & 6,192 & $9 \%$ \\
\hline $2001 / 02$ & 7,490 & $21 \%$ \\
\hline $2002 / 03$ & 8,438 & $13 \%$ \\
\hline $2003 / 04$ & 8,562 & $2 \%$ \\
\hline $2004 / 05$ & 9,867 & $15 \%$ \\
\hline
\end{tabular}

Source: Premier Rugby

\subsection{Key Success Factors}

The success factors obviously first come from the players themselves. This means they must not just be extraordinary players but people who use this sport as a way to communicate with their public. Players must be aware of the position they have with fans, know that they are idols to be copied. So the messages they transmit must always be positive evidence of moral integrity and respect inspiring the club as a whole.

In communication terms, Premier Rugby works to create a common message spread throughout all the clubs, to show group strength and unity for a common objective. This goal is to become one of the best competitions in the world, giving spectators strong emotions through quality performance. The same club must not win all the time - all clubs must have a chance to win. Premier Rugby's match system is designed so that several clubs remain involved in the competition till the end to potentially become the champions.

What we feel are really important in a sports organisation like Premier Rugby are the values shared by the whole organisation. Really important when you consider that sport in general is mainly communicated through publicity more than just advertising (typical for normal products) so a positive, publicly recognised reputation is fundamental. This responsible, ethical attitude reflects both inwards and outwards. This is made explicit by strategies and results in terms of numbers of people involved and, naturally, the positive image for the championship and its champions. A Code of Conduct has been set up for the manner in which clubs and the Premier Rugby League communicate, with specific emphasis on message centralisation.

An example of how League values are put into practice comes from the commitment to training and educating players. They have a work contract with 20 hours a month dedicated to community activities on sponsorship programs involving hospitals, schools and other rugby clubs. Through their involvement, players become an integral part of success. All this adds to increasing fan trust and the size of the community: that is, the number of fans who go to stadiums to watch matches. The reciprocal relationship is well balanced as clubs provide training, a good education level, time for school and in exchange get a good financial return. We must not forget that the goal is to create business. A club has a full-time commitment to all its players, from the youngest of around 20 to the most famous and best known. Premier Rugby invests substantially in career programs to develop talent and organises 
academies to improve players' technical and competitive levels. Along with players, who are the main vehicle for communication with fans, direct fan contact is important to get to know them better. Periodically, clubs do market research to find out about public trends and how a club's reputation has grown over the years. Hence clubs then can intervene when necessary to change negative perceptions or satisfy demand better. For example, they have created ad hoc season packages for single families and for fans wanting to watch matches in groups. There are several ongoing sensitisation initiatives with the general public to attract new fans and increase loyalty in existing fans. Over the last few years, the number of spectators has grown progressively. Naturally this can never reach the high levels attained by other sports such as football (soccer) but results have been excellent so far. Each club has 2 to 4 people involved in community relations organising meetings of various kinds, creating tight involvement for increased match attendances. The concept is to widen the 'pyramid' over the years to increase loyalty and value (Figure 2), going progressively from occasional to frequent spectator, to season ticket holder, company client and shareholder.

Figure 2: The Marketing Pyramid

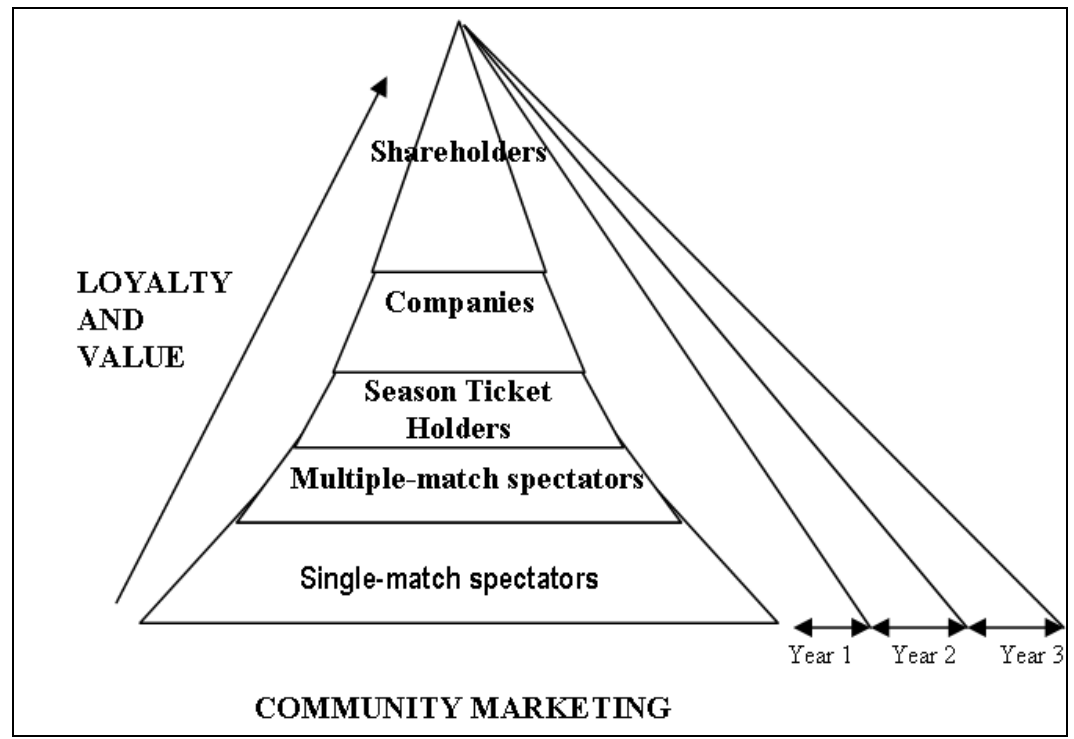

The path taken by Premier Rugby can be shown as a virtuous cycle starting from developing a marketing community through a detailed plan that aims to improve League reputation and increase the number of fans. In turn, this result generates a revenue return that provides greater resources for the teams and for the supply of services. All this leads to a better product for users/fans who are then more motivated and bound to their team. The cycle then goes back to the start, which is the community, and then repeats: with constantly increasing performance levels and reputation for the whole team group (Figure 3). 
Figure 3: The Virtuous Cycle

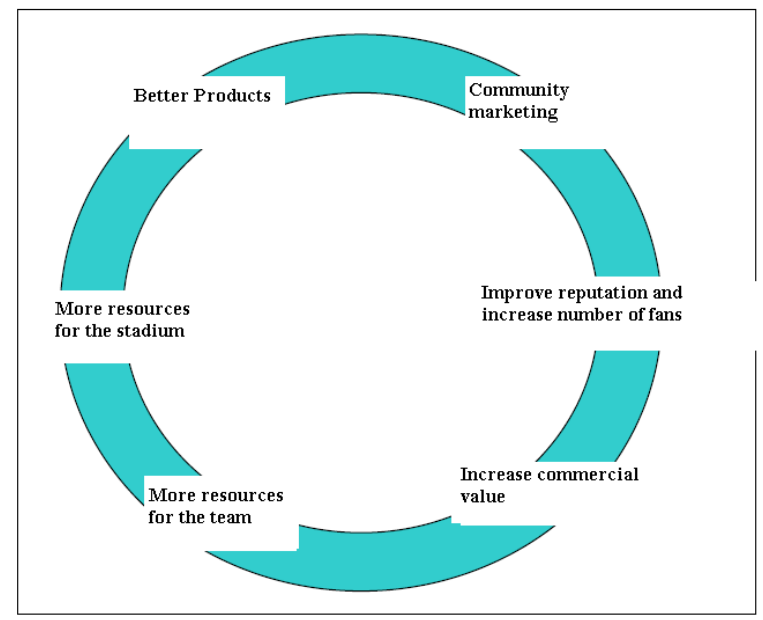

\subsection{Increase in the Number of Stadium Spectators}

The most immediate manifestation of Premier Rugby's positive experience is certainly the increased number of stadium spectators. As Figure 1 shows, the average went up from 5,507 in 1998/99 to 9,867 in 2004/05. The reasons for this growth can be found at both the Club and Championship levels. In particular:

1. at Club level:

- development of Community Marketing;

- focus on ticket sales (especially season tickets, which went from 31,923 in $1999 / 2000$ to 59,265 in $2004 / 05$ ).

2. at Championship level:

- more balanced, competitive matches (with the introduction of salary caps and playoffs);

- higher profile (with strong local/regional media coverage and brand management.

On this front, Premier Rugby wants to strengthen itself even further by highlighting this as the key area. It aims to grow by $10 \%$ a year for the next five years. Indeed, the conviction is that for rugby in England, attendance and thus tickets sold is, as Figure 4 shows, the tree trunk that supports all revenue generation.

Figure 4: How Revenue is Generated

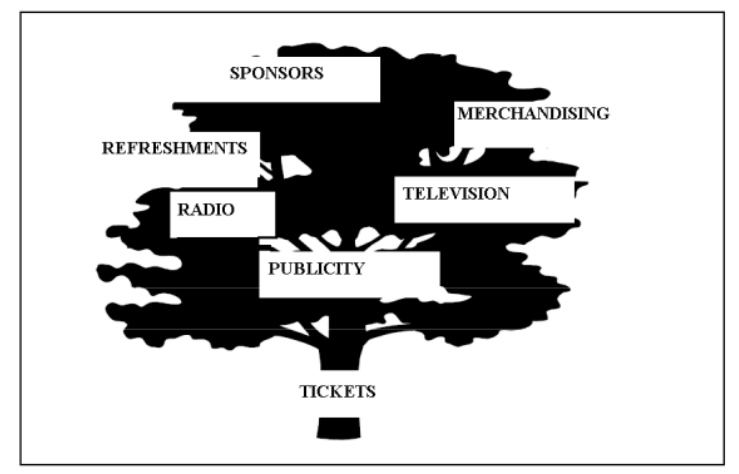




\subsection{Twinning with LIRE}

The spirit of collaboration within healthy, fair competition has also developed at the international level - formalised by an agreement with LIRE in order to improve elite rugby organisation in Italy. In particular, the idea is to encourage the PRA (players' union) to launch an Elite Players Union Association, thus better qualifying Italian players; draft a business plan for community marketing development; create a commercial plan to grow ticket sales; and improve income.

All of this is in the conviction that developing rugby in Italy is of benefit to the entire rugby movement and, thus, for Premier Rugby.

\section{LIRE Experience (Lega Italiana Rugby Eccellenza)}

LIRE was created in 2001 to give expression to the highest rugby level in Italy. Besides typical competition activities - the Super 10 Championship and the Italia Cup - LIRE organises the Finals Shield, the concluding event and most important point in the season (end of May). This is accompanied by All Star Rugby (end of January), a great promotion opportunity with the Italian National Team facing selection for the best foreigners in the Super 10, the Under 21 Finals (in May) and the Italy Cup (in March).

The creation of an Italian Rugby League has come partly from international development in this sport over the last 20 years - from the organisation of the World Championships in 1987 to the prestigious Six Nations Tournament in Italy in 2000. A factor that can help rugby to develop nationally is that it is considered a 'new' sport (though it started in the $19^{\text {th }}$ century). Its strong sport and moral values are based on group spirit but also on individual values, attracting a new public following and consolidating faithful fans. Strength and talent combine with enviable values of propriety and player loyalty in a difficult, complex game.

LIRE's promotion and development goals are both internal and external and focus on the Super 10 Championship so that its activities become increasingly important on the national and international sports scene. Ever since Super 10 first began, great importance has always been attached to programming matches in coordination with National Team activities, the engine of the movement, and to promoting League Events. Ad hoc promotion and communication policies have stimulated media interest and continual, growing visibility (radio, press, TV) essential elements in creating interest for commercial partners.

The internal challenge is based on structural development by the individual clubs and the group as a whole. The Rugby League provides associated clubs with union action, by being adversaries on the field but partners off it. With new shared expansion goals, the movement can come out of the inward focused stage (typical of minor sports) and build a credible, transparent system with a sustainable, stable financial-organisational model.

The targets for relations with the external environment are:

- achieve significant technical and commercial value with the Super 10 Championship;

- continuing excellent inter-change relations with institutional counterparts such as FIR (Italian Rugby Federation) and ERC (European Rugby Cup); 
- added value from further comparison and collaboration in the rugby world as achieved with Premier Rugby;

- maintain links and growing identification with the movement.

Nowadays, organising Club rugby means creating a club peopled with not just players and technical support but also with marketers, communications and press staff - all working in unison. All this goes along with handling sponsor and community relations and making each match an attractive, interesting event for the public. Club rugby development in Italy means all this. It is also the organisation's 'evolution' towards professionalism aimed at, as Premier Rugby declares, a company-like sports club. The Super 10 Clubs must complete several further steps before they reach the level of their English counterparts. We should also point out that Italian Clubs must maintain that special spontaneous amateur club characteristic in management - involving those who want to contribute to the clubs, but without ignoring the professionalism needed to run a top-level Club.

During the LIRE's first three seasons, it needed to increase public awareness of rugby and team activities and gain space against the activities of the National team itself. Rugby, like all sports, has spread and become better known by the public due to International matches, hence the concept of National team developed first (the All Blacks, the Wallabies, the Pumas etc.).

Developing a championship means creating identification around the clubs and players, something carried out in mature rugby nations with factors including first a better technical level for each club and then attractive spectator matches.

Greater spectacle and interest creates appeal for the public and attracts new partners and media. All this is achieved without affecting National team competitiveness. Indeed, it can gain from better external competition (England World Champion in Australia in 2003, Premier League the best Championship in the world). A virtuous cycle exists not just at a sports business system level but at a technical and training level too.

In Italy, the incidence of rugby on TV increased by $196 \%$ between $2001 / 02$ and $2002 / 03$. In the following year it pushed ahead a further $13 \%$. This was helped by the Super 10 matches with rights sold to the public broadcaster RAI and to Tele+ (now Sky). The creation of a TV offering meant growing demand for quality. Promotion and higher public attendance numbers were also worked on to match the new television audience. The Rugby Super $10 \mathrm{TV}$ product will have new frontiers in the future to bring in more potential sports spectators.

By the end of 2004/05, stadium spectator numbers had increased by almost $47 \%$, an effect of on-going targeted projects (an average of 1224 spectators per match).

In 2004/05, both the Championship and the Italy Cup had Official Partners (Findomestic Super 10, SkodaSuperb Cup) interested in the TV and press exposure with offers of integrated communication, but who 'married' (like real partners) Super 10 goals and expectations. Last but not least, we need to consider another rugby potential: being an open-air sport which, across the entire national sports scene, is the only such sport enjoying growth.

Perhaps, as many people say, rugby's only problem today is getting better known. How? Always, more ... and better. For example, the elimination of barriers in Italian rugby stadiums (prior to manifest requests and accusations in football (soccer)) and use of the TMO (video-referee, Television Match Officer) to support the match referee (in the 2004/05 Final Shield this rule was compulsory in several national and 
international tournaments) were given a great deal of importance by the national press this year. Apparently novelties for the Italian sports scene but consolidated habits in the rugby world.

In 2004/05, the Super 10 Clubs were strongly centred in the north, with two teams from the centre-south and eight from Emilia, Veneto and Lombardy, accompanied by competition levelling for the teams at the top and programming aimed at helping them reach the top. Taking part in the European Cup has some limits as of this year. Just 6 out of 10 teams will be admitted. These limits push upwards. Moreover, the second series teams (A series, run by FIR) are fully aware of the programming needed to become a Super 10 Club, from a financial, organisational and competition point of view.

Finally, twinning between LIRE and Premier League means organisational and technical strengthening for each of their Clubs. It involves the League and each Club's organisation. Development of collaborative commercial, sports and organisation projects can create super-capable clubs that reaffirm the importance of national over international matches. 'Know and share to grow' is the main objective - adopting internal rules that lead the Clubs and Leagues to exchange information in order to grow.

The areas involved are Club organisation, with two-way player relations, marketing development, merchandising and communications. Naturally, technical training and the birth and nurturing of future players are also involved, as are major international comparisons at a managerial level, with exchanges on positive experiences and a push for adaptation. 